\title{
JURNAL
}

TEKNOLOGI INFORMASI

\section{Implementasi Algoritma Confix Stripping untuk Pendeteksian Kesalahan pada Tenses}

\author{
Kristien Margi Suryaningrum \\ Teknik Informatika \\ Universitas Bunda Mulia, Jakarta \\ Email: ksuryaningrum@bundamulia.ac.id
}

\begin{abstract}
This study discusses about English tenses error detection using stemming method. The algorithm used in the stemming is Confix Stripping (CS) Algorithm. The algorithm works based on the Bahasa's morphology rules that grouped and encapsulated on affix, prefix, suffix, infix, and their combinations. The CS algorithm uses three components: affixes, rules, and dictionaries. This study is focuses on the implementation of CS algorithm on Information Retrieval System. Evaluated sentences were broken down into words to identify their position in the sentence. The identified verbs will be stemmed to find its basic word, then transformed according the appropriate tense rule. The CS algorithm in the stemming method is used to detect written English tenses from errors.
\end{abstract}

Keywords: Stemming, Verb, Tenses, Detection, Stemmer

\begin{abstract}
Abstrak
Penelitian ini membahas bagaimana cara melakukan deteksi kesalahan penulisan tenses Bahasa Inggris dengan menggunakan metode stemming. Algoritma yang digunakan untuk melakukan stemming adalah algoritma Confix Stripping. Algoritma Confix-Stripping (CS) berdasarkan pada aturan morfologi bahasa Indonesia yang dikelompokkan menjadi satu dan di-enkapsulasi pada imbuhan, termasuk awalan, akhiran, sisipan, dan kombinasi. Algoritma Confix-Stripping (CS) menggunakan tiga komponen: kumpulan imbuhan, rulerule, dan kamus. Pada penelitian ini akan dilakukan analisis penerapan algoritma ConfixStripping (CS) tersebut pada Information Retrieval system. Kalimat yang akan dideteksi dipisahkan menjadi kata per kata untuk kemudian di tentukan posisinya di dalam kalimat. Setelah posisi setiap kata ditentukan, kata yang mendapatkan posisi sebagai verb akan melalui proses stemming untuk mendapatkan bentuk kata dasarnya. Setelah didapatkan kata dasarnya maka bentuknya akan dirubah sesuai dengan bentuk tenses dari kalimat. Penggunaan metode stemming dengan algoritma Confix Stripping dijalankan untuk melakukan deteksi kesalahan penulisan tenses Bahasa Inggris.
\end{abstract}

Kata kunci: Stemming, Verb, Tenses, Deteksi, Kata Dasar, Stemmer 


\section{Pendahuluan}

Penggunaan bahasa asing di Indonesia tidak dapat dihindarkan lagi. Bahasa Inggris merupakan salah satu bahasa asing yang paling banyak digunakan, tidak hanya di Indonesia melainkan di dunia. Maka dari itu, Bahasa Inggris menjadi salah satu pelajaran yang wajib diajarkan di sekolah-sekolah maupun kampus di Indonesia. Namun, Bahasa Inggris bukanlah bahasa yang mudah dikuasai. Oleh karena itu, penting untuk membentuk fondasi dasar pemahaman tentang Bahasa Inggris, salah satunya adalah dengan memberikan pemahaman dasar mengenai tenses.

Berdasarkan pada penjelasan yang dipaparkan di atas dan kenyataan bahwa pada saat ini, penulis akan melakukan penelitian sebuah sistem yang dapat digunakan untuk mendeteksi letak kesalahan penulisan tenses dan melakukan koreksi, serta memberikan informasi yang diharapkan dapat memperkuat fondasi dasar pemahaman mengenai tenses.

\section{Kajian Pustaka}

\section{A. Teknik Stemming}

Stemming adalah proses untuk menggabungkan atau memecahkan setiap varian-varian suatu kata menjadi kata dasar. Stem (akar kata) adalah bagian dari kata yang tersisa setelah dihilangkan imbuhannya (awalan dan akhiran). Contoh : connect adalah stem dari connected, connecting, connection, dan connections. Metode stemming memerlukan input berupa term (kata) yang terdapat dalam dokumen. Sedangkan output-nya berupa stem.

Ada tiga jenis metode stemming, antara lain :

1. Successor Variety (SV), lebih mengutamakan penyusunan huruf dalam kata dibandingkan dengan pertimbangan atas fonem.

2. N-Gram Conflation, ide dasarnya adalah pengelompokan kata-kata secara bersama berdasarkan karakter-karakter (substring) yang teridentifikasi sepanjang $N$ karakter.

3. Affix Removal membuang suffix dan prefix dari term menjadi suatu stem (akar kata). Yang paling sering digunakan adalah algoritma Stemmer karena modelnya sederhana dan effisien.

\section{Teknik Stemming :}

1. Teknik Stemming diperlukan selain untuk memperkecil jumlah indeks yang berbeda dari suatu dokumen, juga untuk melakukan pengelompokan kata-kata lain yang memiliki kata dasar dan arti yang serupa namun memiliki bentuk atau form yang berbeda karena mendapatkan imbuhan yang berbeda. 
2. Sebagai contoh kata bersama, kebersamaan, menyamai, akan di-stem ke root word-nya yaitu "sama". Namun, seperti halnya stopping, kinerja stemming juga bervariasi dan sering tergantung pada domain bahasa yang digunakan.

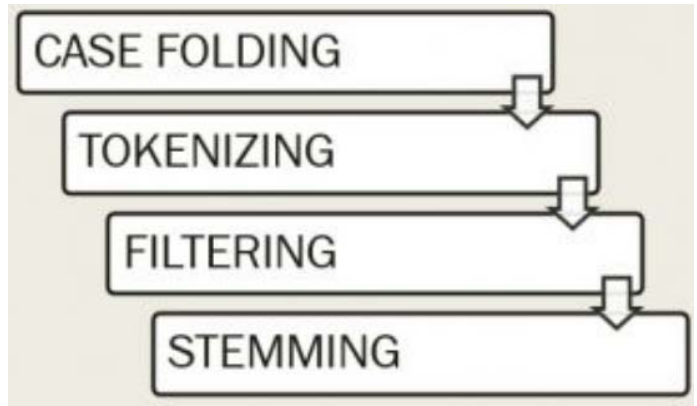

Gambar 1. Tahapan Text Preprocessing

\section{B. Penggunaan Stoplist Dan Stemming Pada “Tahapan Text Preprocessing” Case Folding}

Tidak semua dokumen teks konsisten dalam penggunaan huruf kapital. Oleh karena itu, peran Case Folding dibutuhkan dalam mengkonversi keseluruhan teks dalam dokumen menjadi suatu bentuk standar (biasanya huruf kecil atau lowercase).

Sebagai contoh, user yang ingin mendapatkan informasi "KOMPUTER" dan mengetik "KOMPUTER", "KomPUter", atau "komputer", tetap diberikan hasil retrieval yang sama yakni "komputer". Case folding adalah mengubah semua huruf dalam dokumen menjadi huruf kecil. Hanya huruf 'a' sampai dengan ' $z$ ' yang diterima. Karakter selain huruf dihilangkan dan dianggap delimiter.

\section{Tokenizing}

Tahap Tokenizing adalah tahap pemotongan string input berdasarkan tiap kata yang menyusunnya. Tokenisasi secara garis besar memecah sekumpulan karakter dalam suatu teks ke dalam satuan kata, bagaimana membedakan karakterkarakter tertentu yang dapat diperlakukan sebagai pemisah kata atau bukan. Sebagai contoh karakter whitespace, seperti enter, tabulasi, spasi dianggap sebagai pemisah kata.

\section{Filtering}

Tahap Filtering adalah tahap mengambil kata-kata penting dari hasil token. Bisa menggunakan algoritma stoplist (membuang kata kurang penting) atau wordlist (menyimpan kata penting). Stoplist/stopword adalah kata-kata yang tidak deskriptif yang dapat dibuang dalam pendekatan bag-of-words. Contoh stopwords adalah "yang”, “dan”, “di”, “dari” dan seterusnya. Data stopword dapat diambil dari jurnal Fadillah Z Tala berjudul "A Study of Stemming Effects on Information Retrieval in Bahasa Indonesia”. 
AITI: Jurnal Teknologi Informasi

Volume 16 No. 1 Februari 2019, 88-98

Kata-kata seperti “dari”, “yang”, “di”, dan "ke” adalah beberapa contoh kata-kata yang berfrekuensi tinggi dan dapat ditemukan hampir dalam setiap dokumen (disebut sebagai stopword). Penghilangan stopword ini dapat mengurangi ukuran indeks dan waktu pemrosesan. Selain itu, juga dapat mengurangi level noise.

\section{Verb (Kata Kerja)}

Kata kerja adalah kata yang menunjukkan aktivitas yang dilakukan oleh subyek [4]. Berdasarkan perubahan waktunya, kata kerja dapat digolongkan menjadi regular dan irregular verb.

\section{Regular Verbs}

Regular verbs adalah kata kerja yang perubahannya beraturan dengan menambahkan -d atau -ed di akhir kata [4]. Beberapa aturan penambahan -d dan ed menurut Atqya (2015) adalah sebagai berikut:

1. Jika verbs berakhiran dengan konsonan maka ditambahkan -ed.

2. Jika verbs berakhiran dengan vocal maka ditambahkan -d.

3. Jika verbs berakhiran dengan (-y) maka diubah menjadi (-i) kemudian ditambahkan -ed.

4. Beberapa verbs yang berakhiran dengan konsonan $(g, b, t, r, 1$, atau $p)$ dan diawali oleh huruf vocal, maka konsonan ittu digandakan kemudian ditambahkan -ed.

Irregular Verb

Irregular verb kata kerja yang perubahannya tidak bias diprediksi karena tidak menggunakan penambahan akhiran -d ataupun -ed [4]

\section{Tenses}

Tenses atau tempus (Bahasa Latin) berarti waktu. Jadi, pengungkapan aktifitas atau kegiatan diungkapkan dengan memperhatikan waktu kejadian aktifitas itu [5]

\section{Simple Present Tense}

Pola yang digunakan dalam membentuk sebuah kalimat simple present tense, yaitu:

$$
S+V_{1+s / e s}+O / C
$$

Di mana $\mathrm{S}$ adalah subject (I/you/we/they/she/he/it/names), $V_{1}$ adalah Bare Infinitive (kata kerja bentuk pertama), s/es adalah penambahan akhiran s/es pada akhir verb sesuai subject-nya, $O$ adalah Object dan $C$ adalah Complement.

Aturan penambahan akhiran s/es pada verb adalah sebagai berikut: 
a. Kata kerja (verb) yang berakhir dengan huruf ss, sh, ch, $\mathrm{x}$, dan o, diberi akhiran -es, sedangkan verb yang memiliki akhiran selain huruf-huruf tersebut cukup diberi akhiran -s pada akhir kata tersebut.

b. Kata kerja (verb) yang berakhir dengan huruf y dan huruf sebelumnya adalah huruf konsonan (consonant), maka huruf y tersebut diubah menjadi i dan ditambah akhiran -es pada akhir katanya.

c. Kata kerja (verb) yang berakhir dengan huruf y dan huruf sebelumnya adalah huruf vocal (a/e/i/o/u), maka hanya perlu diberi tambahan akhiran -s pada akhir kata tersebut.

\section{Present Continous Tense}

Pola yang digunakan dalam membentuk sebuah kalimat present continous tense, yaitu:

$$
S+\text { to be }{ }_{(a m, i s, \text { are })}+V_{1 \text { ing }}+O / C
$$

Di mana $\mathrm{S}$ adalah subject (I/you/we/they/she/he/it/names), to be berupa am/is/are, $V_{1}$ ing adalah kata kerja bentuk pertama dengan penambahan akhiran -ing, $O$ adalah Object dan $C$ adalah Complement.

Aturan penambahan akhiran ing pada verb adalah sebagai berikut:

a. Jika kata berakhiran huruf -e maka huruf -e dihilangkan kemudian digantikan dengan -ing.

b. Jika dua huruf terakhir terdiri dari satu vocal dan satu konsonan, maka huruf konsonan itu digandakan dan kemudian tambahkan -ing.

c. Jika tiga huruf terakhir dari sebuah kata terdiri dari dua vocal dan satu konsonan, maka langsung tambahkan ing tanpa harus menggandakan huruf konsonannya.

- Jika dua huruf terakhir dari sebuah kata terdiri dari dua konsonan, maka langsung tambahkan ing tanpa harus menggandakan konsonan.

\section{Simple Past Tense}

Pola yang digunakan dalam membentuk sebuah kalimat simple past tense, yaitu:

$$
S+V_{2}+O / C
$$

Di mana $\mathrm{S}$ adalah subject (I/you/we/they/she/he/it/names), $V_{2}$ adalah kata kerja bentuk kedua, $O$ adalah Object dan $C$ adalah Complement.

\section{Past Continous Tense}

Pola yang digunakan dalam membentuk sebuah kalimat past continous tense, yaitu:

$$
S+\text { to be (was, were })+V_{1 \text { ing }}+O / C
$$


Di mana $S$ adalah subject (I/you/we/they/she/he/it/names), to be berupa $a m / i s / a r e, V_{1}$ ing adalah kata kerja bentuk pertama dengan penambahan akhiran -ing, $O$ adalah Object dan $C$ adalah Complement.

\section{Simple Future Tense}

Pola yang digunakan dalam membentuk sebuah kalimat simple future tense, yaitu:

$$
S+\text { will/shall }+V_{1}+O / C
$$

Di mana $S$ adalah subject (I/you/we/they/she/he/it/names), will/shall (will $\rightarrow$ you, they, she, he, it) (shall $\rightarrow I$, we), $V_{1}$ adalah kata kerja bentuk pertama, $O$ adalah Object dan $C$ adalah Complement.

\section{Future Continous Tense}

Pola yang digunakan dalam membentuk sebuah kalimat future continous tense, yaitu:

$$
S+\text { will/shall }+ \text { be }+V_{1 \text { ing }}+O / C
$$

Di mana $S$ adalah subject (I/you/we/they/she/he/it/names), will/shall (will $\rightarrow$ you, they, she, he, it) (shall $\rightarrow I$, we), be adalah kata bantu setelah will/shall, $V_{1}$ adalah kata kerja bentuk pertama dengan penambahan akhiran -ing, $O$ adalah Object dan $C$ adalah Complement.

\section{Metode Penelitian}

Penelitian ini bersifat terapan, yaitu mencoba untuk menghasilkan sebuah aplikasi/sistem yang dapat membantu user dalam mendekteksi dan mengkoreksi kesalahan pada tenses. Untuk metode penelitian yang dipilih disesuaikan dengan kebutuhan, yaitu metode pengembangan aplikasi/sistem yang mengikuti kaidahkaidah SDLC atau System Development Life Cycle

Dalam membangun aplikasi ini, penulis menggunakan algoritma Confix untuk mendeteksi apakah terdapat kesalahan penulisan pada kalimat yang dimasukkan oleh user.

Langkah-langkah yang dilakukan adalah sebagai berikut:

1. Memisahkan kalimat menjadi kata per kata. Contoh kalimat: he drinks milk every day. Hasil pemisahan: [he], [drinks], [milk], [every], [day]

2. Mencari time signal dari kalimat yang dimasukkan oleh user, Time signal: every day.

3. Mencocokkan time signal ke database untuk menentukan bentuk tenses dari kalimat yang dimasukkan oleh user. Bentuk tenses: simple present.

4. Menentukan posisi dari setiap kata yang terdapat di dalam kalimat 
Subjek $\rightarrow$ he, Verb $\rightarrow$ drinks, Objek/complement $\rightarrow$ setelah verb dan sebelum time signal $\rightarrow$ milk

5. Melakukan stemming pada verb

Sebelum melakukan stemming, verb akan terlebih dahulu di cek bentuknya seperti berikut:

a. Jika $V_{\text {inp }}=V_{2}$, maka $V_{\text {inp }}=V_{1}$,

b. Jika $V_{\text {inp }}=V_{3}$, maka $V_{\text {inp }}=V_{1}$,

c. Jika $\mathrm{V}_{\text {inp }} !=\mathrm{V}_{2}$ dan $\mathrm{V}_{\text {inp }} !=\mathrm{V}_{3}$ dan $\mathrm{V}_{\text {inp }} !=\mathrm{V}_{1}$, cek akhiran pada $\mathrm{V}_{\text {inp }}$ dan melakukan langkah-langkah pada poin $\mathrm{d}$, e, atau $\mathrm{f}$,

d. Jika Vinp diakhiri dengan "s", lakukan pengecekan berikut ini:

Jika bentuk akhiran "sses", hilangkan "es". Jika bentuk akhiran "ies", ubah "ies" menjadi "i". Jika huruf sebelum "s" adalah "e", hilangkan "e" dan "s". Jika huruf sebelum "s" bukanlah huruf "s", hilangkan "s".

e. Jika Vinp diakhiri dengan "eed", hilangkan "d",

f. Jika $V_{\text {inp }}$ diakhiri dengan "ed" atau "ing", hilangkan "ed" atau "ing",

g. Setelah langkah stemming selesai dijalankan, langkah selanjutnya adalah kata hasil stem yang diakhiri dengan huruf "i”, diubah huruf "i"-nya menjadi huruf "y".

\section{Drinks $\rightarrow$ drink}

6. Cek kata hasil stemming ke database, Drink = data di database?

a. Jika ya, maka verb benar. Lanjutkan ke langkah 7-12 disesuaikan dengan bentuk tenses dari kalimat yang dimasukkan oleh user.

b. Jika tidak, maka verb salah. Tampilkan pesan error kepada user.

7. Untuk tenses simple present dilakukan langkah berikut:

a. Jika subjek adalah they, you, we, dan I, maka verb tidak perlu diubah

Drink $\rightarrow$ drink

b. Jika subjek adalah he, she, dan it, maka verb ditambahkan akhiran s/es

Drink $\rightarrow$ drinks

Setelah bentuk verb disesuaikan, kalimat disusun kembali sesuai dengan pola yang ditunjukkan pada Rumus 1.1 dilengkapi dengan time signal.

8. Untuk tenses present continous dilakukan langkah berikut:

a. Jika subjek adalah they, you, dan we, maka: To be $\rightarrow$ are

b. Jika subjek adalah he, she, dan it, maka: To be $\rightarrow$ is

c. Jika subjek adalah $I$, maka: To be $\rightarrow$ am

d. Verb ditambahkan dengan akhiran ing Drink $\rightarrow$ drinking

Setelah to be dan bentuk verb disesuaikan, kalimat disusun kembali sesuai dengan pola yang ditunjukkan pada Rumus 1.2 dilengkapi dengan time signal.

9. Untuk tenses simple past dilakukan langkah berikut:

a. Verb diubah ke bentuk past tense atau bentuk kata kerja kedua Drink $\rightarrow$ drank

Setelah bentuk verb disesuaikan, kalimat disusun kembali sesuai dengan pola yang ditunjukkan pada Rumus 1.3 dilengkapi dengan time signal. 
10. Untuk tenses past continous dilakukan langkah berikut:

a. Jika subjek adalah they, you, dan we, maka: To be $\rightarrow$ were

b. Jika subjek adalah he, she, it, dan I, maka: To be $\rightarrow$ was

c. Verb ditambahkan dengan akhiran ing Drink $\rightarrow$ drinking

Setelah to be dan bentuk verb disesuaikan, kalimat disusun kembali sesuai dengan pola yang ditunjukkan pada Rumus 1.4 dilengkapi dengan time signal.

11. Untuk tenses simple future dilakukan langkah berikut:

a. Jika subjek adalah he, she, it, you, dan they, maka yang digunakan adalah will.

b. Jika subjek adalah $I$, dan we, maka yang digunakan adalah shall

c. Verb tetap pada bentuk kata kerja pertama (tidak mengalami perubahan apapun).

Setelah bentuk will/shall dan bentuk verb disesuaikan, kalimat disusun kembali sesuai dengan pola yang ditunjukkan pada Rumus 1.5 dilengkapi dengan time signal.

12. Untuk tenses future continous dilakukan langkah berikut:

a. Jika subjek adalah he, she, it, you, dan they, maka yang digunakan adalah will.

b. Jika subjek adalah $I$, dan we, maka yang digunakan adalah shall

c. Verb tetap pada bentuk kata kerja pertama (tidak mengalami perubahan apapun).

Setelah bentuk will/shall dan bentuk verb disesuaikan, kalimat disusun kembali sesuai dengan pola yang ditunjukkan pada Rumus 1.5 dilengkapi dengan time signal.

\section{Hasil dan Pembahasan}

Metode perancangan sistem, menggambarkan bagaimana sistem itu berjalan dan berproses. Dan rancangan ini digambarkan menggunakan ERD. Rancangan ERD nya ditunjukkan pada gambar 2 .

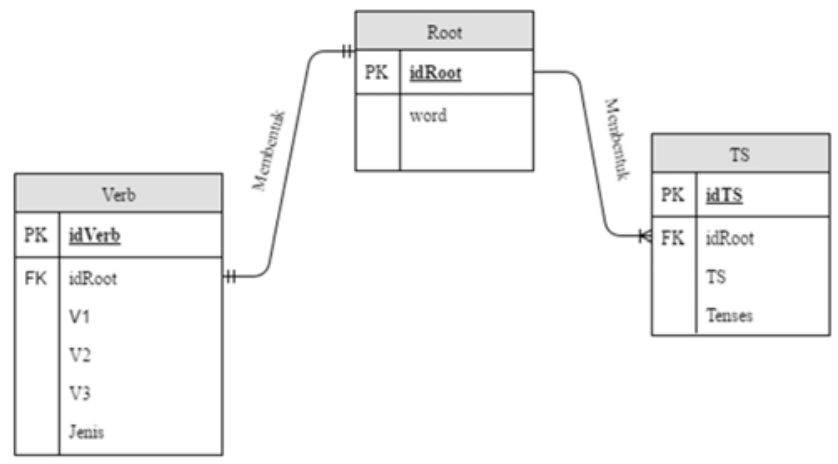

Gambar 2. Rancangan ERD

Hubungan antar tabel data pada aplikasi ditunjukkan oleh Gambar 2. Hubungan antar tabelnya adalah sebagai berikut: 
a. Satu root word membentuk satu verb,

b. Satu root word membentuk banyak time signal.

Perancangan flowchart diagram bertujuan untuk menggambarkan aliran proses dalam sistem. Flowchart diagram dari aplikasi ini ditunjukkan pada Gambar 3.

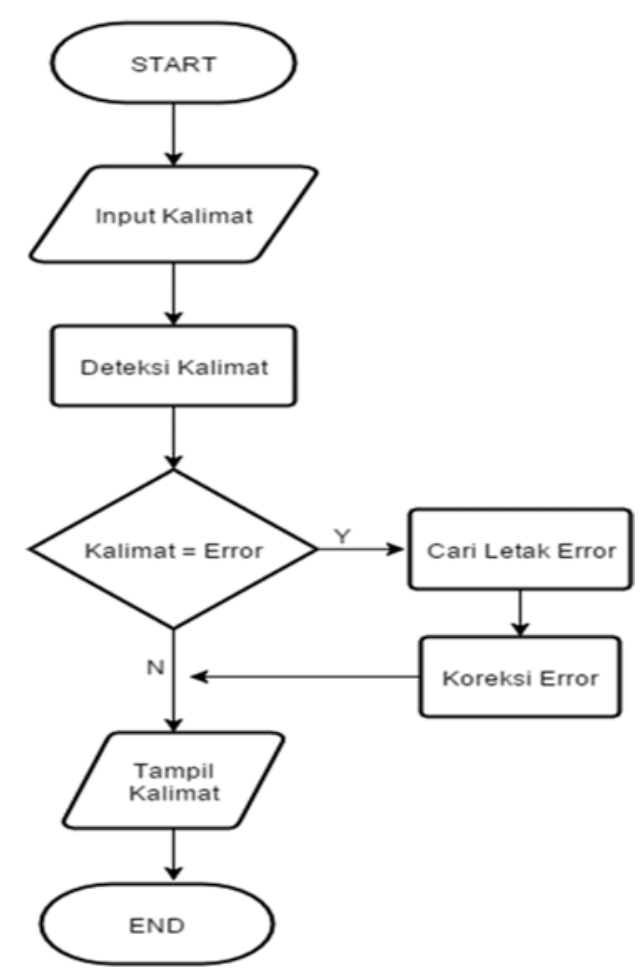

Gambar 3. Flowchart Diagram Sistem

Flowchart diagram yang terlihat pada Gambar 3 menjelaskan saat aplikasi dijalankan hingga hasil deteksi ditampilkan. Penjelasan secara detailnya adalah sebagai berikut:

a. User menjalankan aplikasi. Kegiatan ini diwakili oleh simbol terminator yang bertuliskan "START".

b. User melakukan input kalimat. Kegiatan ini diwakili oleh simbol data berbentuk jajar genjang yang bertuliskan "Input Kalimat".

c. User mengaktifkan proses deteksi kalimat setelah menekan tombol deteksi pada aplikasi. Kegiatan ini diwakili oleh simbol proses berbentuk persegi panjang yang bertuliskan "Deteksi Kalimat".

d. Sistem melakukan pengecekan terhadap kalimat yang dimasukkan oleh user. Terdapat kesalahan atau tidak pada kalimat yang dimasukkan oleh user, menentukan langkah yang akan dilakukan oleh sistem, seperti yang ditunjukkan oleh simbol decision yang bertuliskan "Kalimat = Error".

e. Bila terdapat kesalahan, maka sistem akan mencari dimana letak kesalahan tersebut. Setelah ditemukan letak kesalahannya, sistem akan segera 
AITI: Jurnal Teknologi Informasi

Volume 16 No. 1 Februari 2019, 88-98

melakukan koreksi pada kesalahan tersebut dan hasil koreksinya akan ditampilkan kepada user.

f. Bila tidak terdapat kesalahan, maka sistem akan menampilkan kalimat sesuai dengan yang dimasukkan oleh user.

User disediakan sebuah textbox untuk memasukkan kalimat yang ingin dideteksi. Tombol detect digunakan untuk melakukan proses deteksi. Setelah proses deteksi selesai, hasil dari deteksi ditampilkan pada textbox yang bertuliskan Result. Apabila terdapat kesalahan pada kalimat yang dimasukkan oleh user, maka pesan kesalahan akan tampil pada textbox yang bertuliskan Notes.

Gambar 4 menunjukkan hasil dari keseluruhan proses deteksi. Terlihat pada Gambar 4 bahwa terdapat kesalahan pada kalimat yang dimasukkan oleh user. Kesalahan pertama adalah pola kalimat yang dimasukkan oleh user tidak sesuai dengan bentuk tenses-nya dan kesalahan kedua adalah pada verb yang digunakan dalam kalimat.

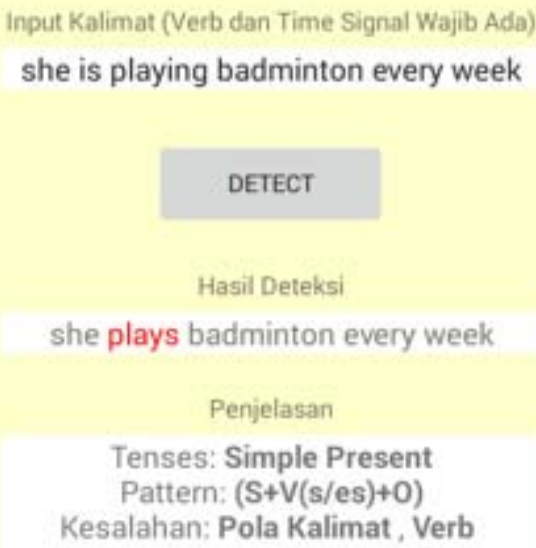

\section{Simpulan}

Gambar 4. Hasil Deteksi

\section{A. Simpulan}

Simpulan yang didapatkan dari hasil penelitian adalah sebagai berikut:

1. Aplikasi pendeteksi kesalahan penulisan tenses dapat digunakan untuk metode pembelajaran tenses, karena aplikasi dapat memperbaiki dan memberikan informasi pada tenses yang salah.

2. Metode stemming dengan algoritma Confix-Stripping (CS) dapat digunakan untuk melakukan pendeteksian kesalahan tenses Bahasa Inggris.

B. Saran 
Saran untuk penelitian ini adalah:

1. Jumlah tenses yang digunakan masih bisa ditambahkan.

2. Aplikasi bisa dikembangkan untuk aplikasi pendeteksian kalimat lebih kompleks

\section{Daftar Pustaka}

[1] Bassil, Youssef, 2012, A Simulation Model for the Waterfall Software Development Life Cycle, International Journal of Engineering \& Technology (iJET), Vol.2. No.5

[2] Kaara, Wahiba. 2013, A New Stemmer to Improve Information Retrieval, International Journal of Network Security \& Its Applications (IJNSA), Vol.5. No.4.

[3] Nathasia, Novi Dian dan Anang Eko Wicaksono, 2011, Penerapan Teknik Kriptografi Stream-Cipher untuk Pengaman Basis Data, Jurnal Basis Data ICT Research Center UNAS, Vol.6. No.1.

[4] Nidhra, Srinivas dan Jagruthi Dondeti, 2012, Black Box and White Box Testing Techniques - A Literature Review, International Journal of Embedded Systems and Applications (IJESA), Vol.2. No.2.

[5] Rani, Ruba, dkk, 2015, Evaluation of Stemming Techniques for Text Classification, International Journal of Computer Science and Mobile Computing (IJCSMC), Vol.4. No.3. hal.165-171.

[6] Tegarden, dkk, (2013), System Analysis and Design with UML/4th Ed, John Wiley and Sons.

[7] Echols, John M. dan Hassan Shadily, (2015), Kamus Inggris Indonesia Updated Edition, PT Gramedia Pustaka Utama, Jakarta.

[8] Nidhra, Srinivas dan Jagruthi Dondeti, 2012, Black Box and White Box Testing Techniques - A Literature Review, International Journal of Embedded Systems and Applications (IJESA), Vol.2. No.2. 